Int. J. Plant Sci. 168(4):421-434. 2007.

(c) 2007 by The University of Chicago. All rights reserved.

$1058-5893 / 2007 / 16804-0005 \$ 15.00$

\title{
HOST FIDELITY OF THE POLLINATOR GUILDS OF SILENE DIOICA AND SILENE LATIFOLIA: POSSIBLE CONSEQUENCES FOR SYMPATRIC HOST RACE DIFFERENTIATION OF A VECTORED PLANT DISEASE
}

\author{
Wilhelmus F. van Putten,* Jelmer A. Elzinga, $\dagger$ and Arjen Biere ${ }^{1, *}$ \\ *Department of Multitrophic Interactions, Netherlands Institute of Ecology (NIOO-KNAW), Boterhoeksestraat 48, \\ NL-6666 GA Heteren, The Netherlands; and HUniversity of Lausanne, Department of Ecology and Evolution, \\ Biophore, CH-1015 Lausanne, Switzerland
}

\begin{abstract}
Host fidelity can play an important role in sympatric host race formation of phytophagous insects by providing a mechanism for prezygotic reproductive isolation. Similarly, but less recognized, host fidelity of insects could provide a mechanism for maintaining host-specific differentiation among insect-vectored pathogens. We studied the transfer of fluorescent dye-mimicking spores of the pollinator-transmitted anther smut fungus Microbotryum violaceum in experimental plots of two of its closely related hosts, Silene dioica and Silene latifolia. Mean rates of diurnal interspecific transfer were $26 \%$ from S. latifolia to S. dioica and $34 \%$ in the reverse direction, suggesting that host fidelity of pollinators per se cannot account for the maintenance of genetically differentiated host races of this fungus observed in sympatry. In a large natural sympatric population of the two hosts, S. dioica flowers experienced a sixfold higher probability of receiving spores from conspecifics than from heterospecifics during the time frame of susceptibility to successful systemic infection due to their earlier onset of flowering. Also, spores from heterospecifics were an order of magnitude farther away than spores from conspecifics. We therefore speculate that the observed sympatric host-specific differentiation is due to a combination of factors, including vector behavior and host spatial and temporal structure.
\end{abstract}

Keywords: disease vector, fungal pathogen, host race, insect pollinator, sympatry.

\section{Introduction}

Host preference or fidelity can play an important role in sympatric host race formation in phytophagous insects by providing a mechanism for prezygotic reproductive isolation (Feder et al. 1994; Wood et al. 1999; Berlocher and Feder 2002). In addition, evolution and maintenance of host races generally require host-related fitness trade-offs to overcome leakiness in host fidelity (Feder 1998), for instance, by antagonistic pleiotropy of genes involved in performance on different hosts (Dieckmann and Doebeli 1999; Kondrashov and Kondrashov 1999). However, empirical evidence for such antagonistic pleiotropy is scant; genetic correlations between the performance of phytophagous insects on different host species are often nonsignificant or positive (see Fry 1996; but see Via et al. 2000). The role of host preference or fidelity in prezygotic reproductive isolation among strains of phytopathogenic fungi has received much less attention. Host preference is usually not considered a factor in fungal speciation models (Brasier 1987; Taylor et al. 1999). Although fungi are usually dispersed by wind, many phytopathogenic fungi are vectored by insects (Roy 1994). Examples are Dutch elm disease, vectored by bark beetles (Ingold 1971), and the floral smut Anthracoidea, vectored by shining flower beetles

1 Author for correspondence; telephone 31-26-4791212; fax 3126-4723227; e-mail a.biere@nioo.knaw.nl.

Manuscript received August 2006; revised manuscript received November 2006.
(Ingvarsson and Ericson 1998). In these cases, host fidelity of the vectors rather than of the pathogens could promote reproductive isolation among fungal strains on different host species. Obviously, genetic coupling between loci involved in host preference and assortative mating, which generally promotes host race formation (Felsenstein 1981), could not evolve in such cases. However, as in insects that mate on the preferred host plant (Bush and Diehl 1982) or that return to the parental habitat before mating (Rice and Salt 1990), behavioral coupling between (vector-mediated) host-preference and fungal assortative mating could occur in phytopathogenic fungi that mate on the host selected by the vector.

In this article, we study host fidelity of insect vectors of a fungal plant disease that infects two sympatric host plant species to assess whether host fidelity could mediate prezygotic isolation of fungal demes on these two host species. In addition, we study the extent of phenological asynchrony and spatial structure of the two host species in a sympatric population that could be additional forces reducing mating between fungal demes from the two host species. The plant disease is the anther smut fungus Microbotryum violaceum (Pers.: Pers) Deml and Oberw. (=Ustilago violacea [Pers.] Fuckel) (Ustilaginaceae) (Vánky 1998). It is a well-studied basidiomycete with a wide host range within the Pink family (Caryophyllaceae) (Thrall et al. 1993) that produces its teliospores in the anthers of host flowers. In female plants of dioecious host species, fungal infection leads to early arrestment of ovary development and stimulation of the development of staminal rudiments 
into stamens with anthers that contain spores instead of pollen. Teliospores are transmitted by insect visitors that serve both as pollinators of the plant and as vectors of the disease (e.g., Jennersten 1983). The existence of host races in M. violaceum that are specialized on different sets of host species has been described as early as the 1920s (Zillig 1921). Two of the host species of $M$. violaceum are the closely related white campion, Silene latifolia Poiret (=Silene alba [Miller] Krause) and red campion, Silene dioica (L.) Clairv. (Caryophyllaceae). Silene latifolia is a dioecious, short-lived perennial from sandy open, disturbed habitats and borders of arable land with a typical moth-pollination syndrome (Baker 1961), producing heavily scented white flowers that open at dusk (Jürgens et al. 2002). Silene dioica is a dioecious perennial that occurs mainly in shady, humid habitats, such as woodland borders, that is primarily pollinated by bumblebees (Kay et al. 1984). In areas where their habitats overlap, sympatric populations occur in which both host species can be infected by the anther smut and where the host species may hybridize (Baker 1947; Goulson and Jerrim 1997). Recent studies have demonstrated that anther smut isolates from allopatric populations of $S$. dioica and S. latifolia are strongly differentiated for a number of genetic markers, including karyotype (Perlin 1996; Perlin et al. 1997), a sporidial colony color (Garber et al. 1975) marker (Biere and Honders 1996a; van Putten 2002) and microsatellite loci (Bucheli et al. 2001; van Putten et al. 2005). The extent of differentiation among anther smut isolates from the two host species appears to be smaller among samples from sympatric and parapatric host populations than among isolates from allopatric host populations (van Putten et al. 2005), but even in sympatry, host-specific differentiation can be observed for sporidial colony color (Biere and Honders 1996a; van Putten 2002) and for some of the microsatellite loci (van Putten et al. 2005).

This raises the question of how such host-related genetic differentiation is maintained in sympatry. Evidence for tradeoffs in performance between fungal isolates on the two host species is scant. A cross-inoculation experiment showed that fungal strains produced more teliospores per infected plant on conspecifics than on heterospecifics of the host of origin (Biere and Honders 1996a), but this was observed only in male hosts. Furthermore, no trade-off was observed for infection success. On the contrary, a competition experiment (van Putten et al. 2003) showed that isolates from S. latifolia outcompeted isolates from $S$. dioica on both host species because of their faster conjugation rates and shorter latent period. Therefore, we studied whether host fidelity of the pollinator guilds of $S$. dioica and $S$. latifolia could be a factor contributing to the maintenance of these host races in sympatry. To study patterns of spore transfer between and within the two host species, we set up experimental sympatric plant populations of $S$. dioica and S. latifolia and used fluorescent dyes as traceable teliospore surrogates to explore the visitation patterns of the pollinator community. These experiments show the maximum rates of interspecific transfer in fully mixed and synchronized populations. In addition, we used data from a well-mixed natural sympatric population to explore to what extent interspecific transfer may be restricted by spatial and temporal separation between host species due to asynchrony in flowering phenology and small-scale patchiness in host species distribution. We address the following questions: (1) Do different guilds of pollinators discriminate between $S$. dioica and $S$. latifolia in a mixed experimental array and show host fidelity? (2) What is the frequency of interspecific visitation between both host species; i.e., to what extent would an assortative visitation pattern with respect to host species provide a basis for the maintenance of host races of M. violaceum in sympatric host populations? (3) If leakiness in fidelity occurs, to what extent are opportunities for exchange diminished by the spatial and temporal structure of hosts in a truly sympatric host population?

\section{Material and Methods}

\section{Plants}

Seeds of Silene latifolia and Silene dioica, originating from allopatric populations in the Netherlands sampled in 1997 and 1998, were germinated in petri dishes on filter paper moistened with demineralized water at a density of ca. 25 seeds per petri dish $(9 \mathrm{~cm}$ diameter $)$ in a growth cabinet (16L : $8 \mathrm{D}, 21^{\circ} \mathrm{C}$ day temperature $/ 15^{\circ} \mathrm{C}$ night temperature) after a vernalization period of $3 \mathrm{~d}$ at $4^{\circ} \mathrm{C}$. Nearly all seeds germinated within a week. In total, $750 \mathrm{~S}$. dioica and $500 \mathrm{~S}$. latifolia were potted $2 \mathrm{wk}$ after vernalization in containers (12 cm diameter) and grown in a climate-controlled greenhouse $\left(16 \mathrm{~L}: 8 \mathrm{D}, 21^{\circ} \mathrm{C}\right)$ until flowering.

\section{Experimental Design}

Because different pollinator guilds may be active during daytime and nighttime (Groman and Pellmyr 1999; Young 2002) and patch size often affects foraging patterns of pollinators (Sowig 1989), we ran four experiments that differed in patch size of host plants and duration of plant visitation (diurnal vs. diurnal plus nocturnal visitation) but that had the same basic layout. A total of 64 containers, each holding one male and one female flowering plant of the same species, were placed in a grid of $8 \times 8$ (fig. 1), so that all neighboring containers were separated by $1 \mathrm{~m}$. Plants in the containers at the two corner positions of either the west (fig. 1, diamonds) or east side (fig. 1, squares) of the plot served as source plants. A few milligrams of fluorescent dye (Radiant Technologies, Richmond, CA) were placed on the anthers and filaments of 10 open flowers of the male plant and on the pistils of eight open flowers on the female plant in the source containers (most female plants had fewer than 10 flowers simultaneously open) with a toothpick. Red fluorescent dye was applied to $S$. dioica source plants (fig. $1, R$ ) and used as a mimic of Microbotryum violaceum teliospores of $S$. dioica origin. Yellow fluorescent dye was applied to S. latifolia source plants (fig. 1, Y) and used as a mimic of M. violaceum teliospores of $S$. latifolia origin. Just after sunset, all open flowers on all 124 recipient plants in a plot were examined for the presence of red or yellow dye using a portable 366-nm UV lamp (ML-49, UVP, Upland, CA). In total, 16,837 flowers were examined.

The four experiments were set up sequentially during the season in 2000. Each experiment was repeated four times, 


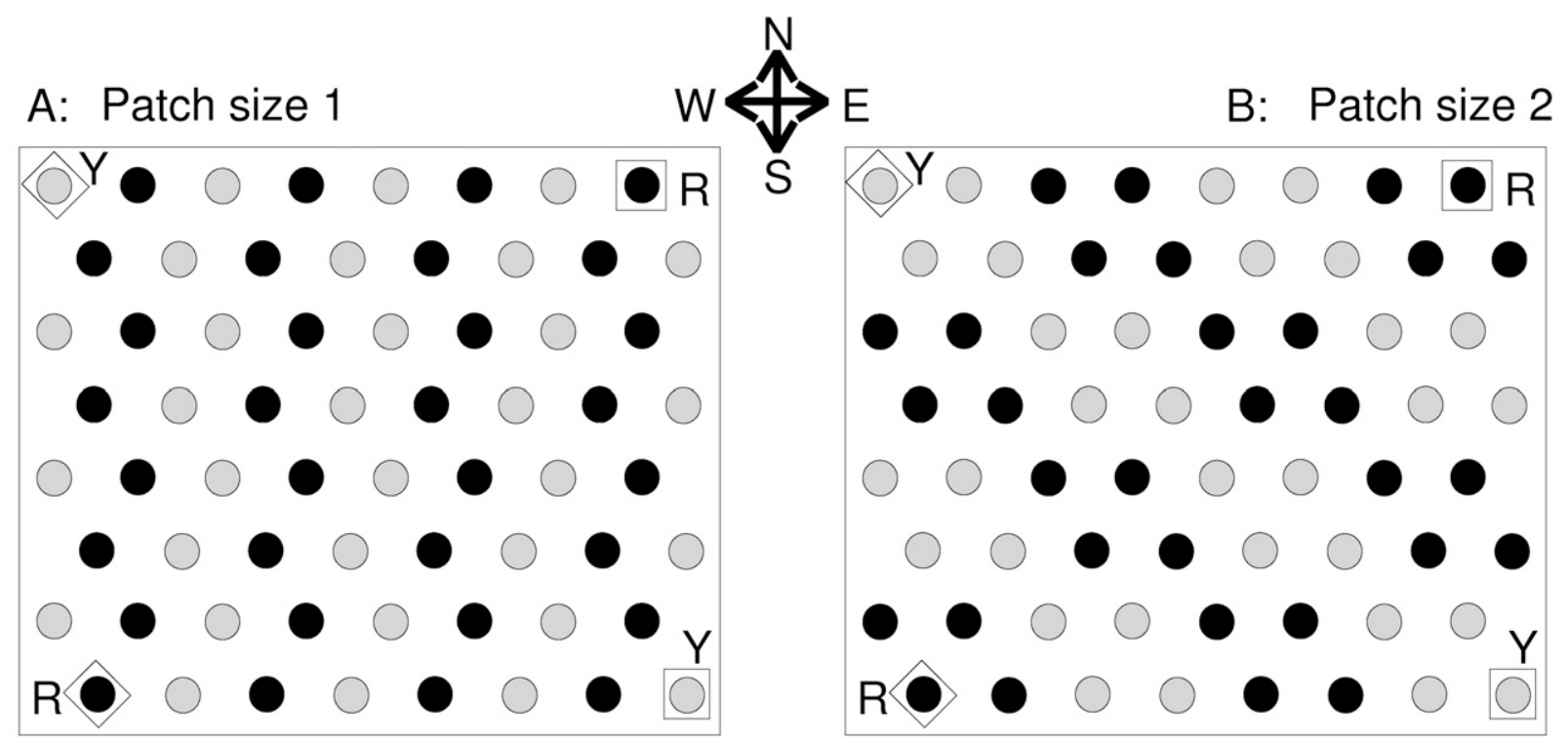

Fig. 1 Schematic setup of experimental plots. Each of 64 containers includes one female and one male plant of Silene dioica (black circles) or Silene latifolia (gray circles). A, Experiments D1 and DN1, with alternating host species (patch size $=1$ ). B, Experiments D2 and DN2, with host species in patches of $2 \times 2$ (patch size $=2$ ). $Y=$ containers with source plants with yellow dye; $R=$ containers with source plants with red dye. Containers on the west side of the plot are indicated by diamonds; those on the east side are indicated by squares. Distance between containers is $1 \mathrm{~m}$.

twice with dye applied to plants at the corners of the west side and twice with dye applied to plants at the corners of the east side, to correct for potential dominant wind influences. In experiment $1(\mathrm{DN} 1$; day + night, patch size $=1)$, containers with $S$. latifolia and $S$. dioica plants were alternated in a checkerboard pattern (fig. 1A). Fluorescent dye was applied just before sunset. Four replicates were run between June 20 and 29. In experiment 2 (DN2; day + night, patch size $=2$ ), containers with $S$. latifolia and $S$. dioica plants were placed in patches of $2 \times 2$ containers with the same species (alternating $S$. latifolia and S. dioica patches; fig. 1B). Fluorescent dye was applied just before sunset. Four replicates were run between July 18 and 31. Experiment 3 (D1; daytime only, patch size $=1$ ) was similar to experiment 1, except that fluorescent dye was applied just before sunrise. For this setup, there were only two (mirrored) replicates because of unfavorable weather conditions at the end of the season that were run on August 31 and September 13. Experiment $4(\mathrm{D} 2$; daytime only, patch size $=2)$ was similar to experiment 2 but with fluorescent dye applied just before sunrise. Four replicates were run between August 9 and 24 . In experiments 3 and 4 , source plants were removed at sunset of the same day, and dye transmissions were determined after sunset.

For each experimental day (and night), daylength was determined, and mean day and night values for temperature, wind, sun radiation, and rain were recorded. The use of fluorescent dye as a pollen analogue has been criticized (Thomson et al. 1986) because dye particles are often smaller than pollen grains. Indeed, dye particles are much smaller than pollen of S. latifolia (35-60 $\mu \mathrm{m}$; Prentice et al. 1984) but are similar to teliospores in size (6-9 $\mu \mathrm{m}$; Zogg 1985). Therefore, although dye particles are more irregular in shape, we think that they may be a good analogue of fungal spores (Shykoff and Bucheli 1995).

\section{Direct Observations of Visitors}

During experiments 1 and 2, night insect visitors to flowers in the plot were caught on 10 occasions between 2300 and 0100 hours, identified and checked for the presence of fluorescent dye, and released afterward. During experiments 3 and 4, daily visitors to flowers in the plot were observed and identified on six occasions during a total observation period of $215 \mathrm{~min}$. Some visitors were also caught and checked for the presence of fluorescent dye.

\section{Spatial and Temporal Host Structure in Sympatry}

In addition to host fidelity of vectors, differences in phenology and spatial substructure of host species within sympatric populations may constitute potential barriers to gene flow between fungal demes from the two host species. We therefore analyzed data on phenology and spatial distribution of the two host species in a large sympatric population (Norg; lat. $6^{\circ} 30^{\prime} \mathrm{E}$, long. $53^{\circ} 06^{\prime} \mathrm{N}$ ) that were obtained during a previous study conducted in 1992 and 1993 (Biere and Honders 1996b). This population represents one of the largest, most closely sympatric, and most balanced host populations with respect to population sizes and disease incidence in the two host species that we know of in the Netherlands. In 1992, the population consisted of $785 \mathrm{~S}$. dioica and $698 \mathrm{~S}$. latifolia flowering plants, of which $22.5 \%$ and $19.3 \%$, respectively, were systemically infected by M. violaceum. During 26 weekly censuses between late April and late October, every $S$. latifolia and $S$. dioica plant that had initiated 
flowering that week (cohort $k$ ) was mapped to the nearest decimeter, and its sex, disease status, and cohort number were recorded. Weekly counts of the number of healthy and diseased open flowers per plant were made for a subset of 369 plants. This subset was selected in such a way that all cohorts were well represented in the sample; from every cohort of $N_{k}$ plants per species, sex, and disease status, we randomly selected $n_{k}$ plants, up to a maximum of seven. To estimate the total number of healthy $\left(X_{i, k}\right)$ and diseased $\left(Y_{i, k}\right)$ flowers produced by species $i$ in week $k$ in the whole population, we simply multiplied the total number of open flowers on plants from each cohort at census $k$ by $N_{k} / n k$ for the corresponding species, sex, and disease status. Because open flowers generally last for less than a week, the estimates are likely to be underestimates of the true numbers of flowers produced by the plants. The fraction of all flowers produced by host species $i$ during the season that was exposed to spores from conspecifics $\left(C_{i}\right)$ was estimated as

$$
C_{i}=\sum_{k=1}^{26}\left(\frac{f X_{i, k} \times f Y_{i, k}}{f Y_{i, k}+f Y_{j, k}}\right),
$$

where subscripts $i$ and $j$ refer to the two different host species and $f X_{i, k}$ and $f Y_{i, k}$ are the fraction of the total number of healthy and diseased flowers produced by species $i$ that were produced during week $k$, respectively. This estimate quantifies the effect of differences in phenology between the two host species and is independent of differences in population size or disease incidence between the two host species, although these were quite similar in the study population.

In addition, on the basis of the mapped position of each plant, we calculated the distance of each plant that was not systemically diseased at the start of the season to the nearest conspecific (DistC) and heterospecific (DistH) inoculum source in the population and calculated the frequency distribution of the distances to heterospecific relative to conspecific inoculum sources (DistH - DistC).

\section{Data Analysis}

Each of the four pollinator visitation experiments was analyzed separately. First, we analyzed overall effects of host species (SP), host sex (SX), and replicate (R) on floral display (number of open flowers on a plant), visitation frequency (proportion of open flowers with dye from any source), heterospecific visitation rate (proportion of visits originating from a heterospecific dye source), and mixed visitation rate (proportion of visited flowers carrying dye from both a conspecific and a heterospecific source), neglecting within-plot distances to source plants. For these analyses, we used generalized linear models (SAS, ver. 8, procedure GENMOD, SAS Institute, Cary, NC) with an identity link function and a normal error distribution. Scaled deviances were used to correct for overdispersion. Next, we performed more detailed analyses of the effect of donor species (DS), distance to the donor species (D), sex of recipient plant (SX), and replicate (R) on visitation frequency of the two recipient species to gain insight in differences in the decay rate of the visitation frequency with increasing distance from conspecific and heterospecific dye sources using the same type of models. Distances be- tween the source of the fluorescent dye and recipient plants were calculated from the center of the source container to the center of the recipient container, neglecting actual positions of plants and flowers inside the container. To illustrate differences in how far conspecific and heterospecific dye can be transmitted across recipient hosts, we used parameter estimates from a fitted exponential decay function $y=a e^{-b x}$, where $y=$ visitation frequency and $x=$ distance to the corresponding dye source (see Gregory 1968; Jeger 1990), to estimate the theoretical distance from conspecific and heterospecific source plants at which the average proportion of recipient flowers carrying dye would become smaller than $1 \%$.

\section{Results}

\section{Overall Visitation Patterns}

Floral display differed between host species and sexes (fig. $2 A$; table 1). Male and female Silene dioica had on average 16.5 and 7.5 flowers simultaneously open per plant, respectively, whereas male and female Silene latifolia displayed on average 8.8 and 6.8 open flowers per plant. The intersexual difference in floral display was significantly smaller in $S$. latifolia than in $S$. dioica (fig. $2 A$; table 1 , interaction species $\times$ sex). The absolute number of flowers per plant that carried red or yellow dye at the end of the 16- or 24-h visitation periods was also higher for $S$. dioica than for S. latifolia and higher for males than for females in all experiments (fig. $2 A)$. However, the proportion of flowers per plant that carried red or yellow dye (hereafter "visitation frequency") did not show consistent differences between plant species or between sexes across experiments (fig. 2B). In experiment $\mathrm{DN} 1$, visitation frequency was higher for $S$. dioica $(50.7 \%)$ than for $S$. latifolia $(40.7 \%$ ) (fig. $2 B$; table 1 ); in experiments DN2 and D1, the difference depended on host sex (table 1, interaction species $\times \operatorname{sex}$ ), and in experiment D2, visitation frequency was independent of host species and sex (table 1).

\section{Host Fidelity}

Heterospecific visitation rates, i.e., the proportion of all visits evidenced by the presence of red or yellow dye on flowers of recipient plants that originated from a heterospecific donor, were all significantly smaller than $50 \%$ (fig. 2C), indicating some pollinator specificity with respect to host species, except for daytime visitation (D1 and D2) of S. latifolia. However, interspecific transfer was still considerable, on average $35.1 \%$. The proportion of heterospecific visits differed between host species (fig. 2C; table 1), indicating that interspecific transfer between host species was asymmetric. On average, $42.0 \%$ of the dye records on flowers of S. latifolia originated from the heterospecific $S$. dioica source plant, whereas on average only $28.2 \%$ of the dye records on flowers of $S$. dioica originated from the heterospecific S. latifolia source plants (fig. 2C). The high proportion of heterospecific visits to $S$. latifolia was due mainly to daytime visitors. During daytime (experiments D1 and D2), S. latifolia received $51.5 \%$ heterospecific visits. When nighttime visitation was included in the experiments (DN1 and DN2), the proportion of heterospecific visits dropped to $34.2 \%$ (fig. 2C). For $S$. dioica, the difference in the proportion of heterospecific visits 

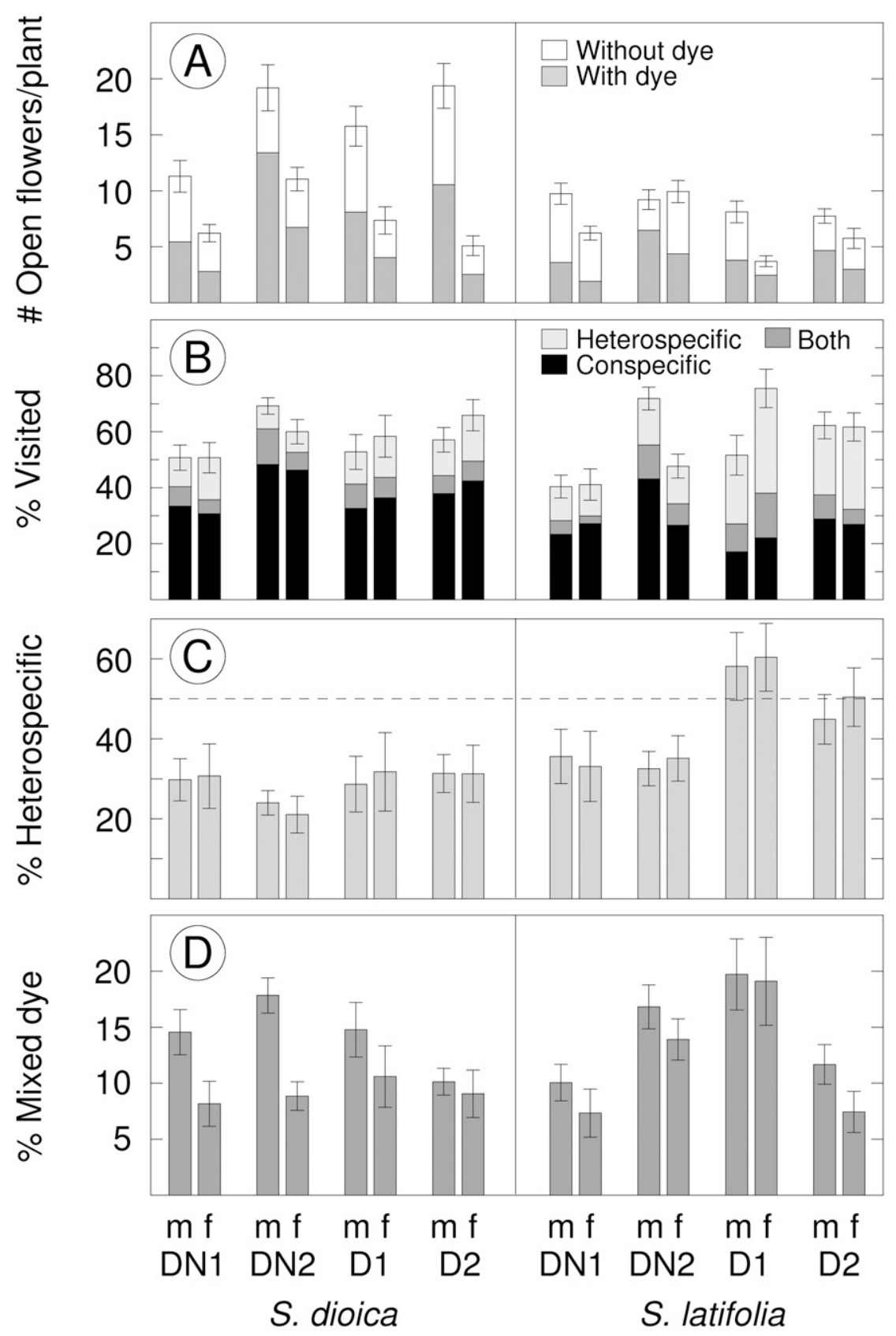

Fig. 2 Floral display and visitation characteristics of male $(m)$ and female $(f)$ Silene dioica (left) and Silene latifolia (right) plants in four experiments (DN1, DN2, D1, D2). A, Average number of simultaneously open flowers per plant. B, Proportion of open flowers visited. C, Proportion of visited flowers with dye from heterospecific origin. D, Proportion of flowers with dye of both conspecific and heterospecific origin. Error bars are $95 \%$ confidence limits.

between daytime $(30.9 \%)$ and diurnal $(26.4 \%)$ visitation was much smaller. During daytime, the proportion of heterospecific visits to $S$. latifolia was higher when the two host species were located in alternating positions $(\mathrm{D} 1:$ mean $=59.3 \%, 95 \%$ confidence limits $[\mathrm{CL}]=53.3 \%-65.2 \%$ ) than when they were placed in small patches (D2: mean $=47.6 \%, C L=42.8 \%-$ $52.4 \%$ ). Similarly, over a $24-\mathrm{h}$ period, the proportion of heterospecific visits to $S$. dioica was higher when the two host species were located in alternating positions (DN1: mean $=30.2 \%, C L=25.6 \%-34.7 \%)$ than when they were placed in small patches $(\mathrm{DN} 2$ : mean $=22.6 \%, \mathrm{CL}=19.8 \%-$ $25.3 \%)$. The proportion of heterospecific visits was not significantly affected by host sex (table 1 ). Overall, $12.3 \%$ of the visited flowers per plant contained dye from both donor species (percentage mixed; fig. 2D). Because dye was used as a mimic for fungal spores, this would indicate opportunities for mating among fungal demes originating from the two hostspecies within a flower. Over a 24-h period (experiments 


\section{Table 1}

\section{Effects of Host Species (SP; Silene latifolia or Silene dioica), Host Sex (SX), and Replicate Experiment (R) on Floral Display and Flower Visitation Characteristics}

\begin{tabular}{|c|c|c|c|c|c|}
\hline Source of variation & df & DN1 & DN2 & $\mathrm{D} 1^{\mathrm{a}}$ & D2 \\
\hline \multicolumn{6}{|c|}{ No. open flowers per plant: } \\
\hline $\mathrm{R}$ & 3 & $45.9^{* \ldots *}$ & $2.9^{*}$ & $22.5^{* * * *}$ & $23.4^{* * * *}$ \\
\hline SP & 1 & $4.5^{*}$ & $72.3^{* \ldots * n}$ & $95.0^{* \ldots * *}$ & $100.1^{\ldots \ldots *}$ \\
\hline SX & 1 & $114.7^{* * * *}$ & $31.9^{* * * *}$ & $122.1^{* * * *}$ & $222.3^{* * * n}$ \\
\hline $\mathrm{SP} \times \mathrm{SX}$ & 1 & $\ldots$ & $46.6^{\text {*** }}$ & 12.0 & $129.2^{* * * *}$ \\
\hline $\mathrm{R} \times \mathrm{SP}$ & 3 & $4.7^{* *}$ & .5 & $\ldots$ & $4.8^{* * *}$ \\
\hline $\mathrm{R} \times \mathrm{SX}$ & 3 & $6.6^{* *}$ & $6.3^{* \ldots *}$ & $\ldots$ & $9.4^{* \ldots * *}$ \\
\hline $\mathrm{R} \times \mathrm{SP} \times \mathrm{SX}$ & 3 & $\ldots$ & $5.2^{* * *}$ & $\ldots$ & $9.6^{* \ldots * n}$ \\
\hline Error df & & 436 & 439 & 243 & 479 \\
\hline \multicolumn{6}{|c|}{$\begin{array}{l}\text { Proportion of open } \\
\text { flowers with dye: }\end{array}$} \\
\hline $\mathrm{R}$ & 3 & $3.3^{*}$ & $14.4^{\text {**** }}$ & .6 & $7.0^{* * *}$ \\
\hline SP & 1 & $25.5^{* * * *}$ & $10.7^{* * *}$ & .7 & 3.3 \\
\hline SX & 1 & $4.5^{\prime \prime}$ & $82.8^{* \ldots *}$ & $8.1^{\prime * *}$ & 3.5 \\
\hline $\mathrm{SP} \times \mathrm{SX}$ & 1 & $\ldots$ & $15.6^{* * * *}$ & $3.9^{*}$ & $\ldots$ \\
\hline $\mathrm{R} \times \mathrm{SP}$ & 3 & $6.5^{*}$ & $3.1^{*}$ & $\ldots$ & $\ldots$ \\
\hline $\mathrm{R} \times \mathrm{SX}$ & 3 & $\ldots$ & $9.4^{* * * *}$ & $\ldots$ & $\ldots$ \\
\hline $\mathrm{R} \times \mathrm{SP} \times \mathrm{SX}$ & 3 & $\ldots$ & $3.0^{*}$ & & \\
\hline Error df & & 442 & 480 & 243 & 489 \\
\hline \multicolumn{6}{|c|}{$\begin{array}{l}\text { Proportion of visits } \\
\text { originating from a } \\
\text { heterospecific source: }\end{array}$} \\
\hline $\mathrm{R}$ & 3 & 1.3 & 2.5 & 1.2 & 1.4 \\
\hline SP & 1 & 3.0 & $54.8^{\ldots * *}$ & $31.8^{* * * *}$ & $31.8^{* \ldots *}$ \\
\hline SX & 1 & .0 & .0 & .1 & 3.5 \\
\hline $\mathrm{R} \times \mathrm{SP}$ & 3 & $4.0^{* * *}$ & $3.6^{*}$ & $5.8^{*}$ & $69.4^{* * *}$ \\
\hline Error df & & 388 & 472 & 235 & 449 \\
\hline \multicolumn{6}{|c|}{$\begin{array}{l}\text { Proportion of visited } \\
\quad \text { flowers with mixed dye: }\end{array}$} \\
\hline $\mathrm{R}$ & 3 & $4.1^{* *}$ & $16.2^{* * * *}$ & 2.3 & $4.1^{* * *}$ \\
\hline SP & 1 & 2.2 & 1.4 & .8 & .0 \\
\hline SX & 1 & $4.0^{\prime \prime}$ & $16.1^{* \ldots * n}$ & .0 & 2.5 \\
\hline $\mathrm{R} \times \mathrm{SX}$ & 3 & $\ldots$ & $3.3^{*}$ & 3.5 & 1.0 \\
\hline $\mathrm{R} \times \mathrm{SP} \times \mathrm{SX}$ & 3 & $\begin{array}{l}\cdots \\
\cdots\end{array}$ & $\ldots$ & $5.0^{*}$ & $3.5^{\prime \prime}$ \\
\hline Error df & & 391 & 472 & 232 & 441 \\
\hline
\end{tabular}

Note. Data for four different experiments $(\mathrm{DN}=$ day and night visitation; $\mathrm{D}=$ daytime visitation; $1=$ plant species alternating; $2=$ plant species in small patches). Values are quasi- $F$ values from GLM analyses. Ellipses = nonsignificant effects removed from the model.

a For experiment D1, the degrees of freedom for replicate and interactions with replicate are 1 instead of 3 .

${ }^{*} P<0.05$.

** $P<0.01$

${ }^{* * *} P<0.001$.

DN1 and DN2), the proportion of visited flowers with dye of mixed origin was significantly higher in males (mean $=14.9 \%$, $\mathrm{CL}=13.1 \%-16.7 \%$ ) than in females (mean $=9.9 \%, \mathrm{CL}=$ $8.1 \%-11.7 \%$ ) (fig. $2 D$; table 1 ).

\section{Effect of Distance on Fraction of Heterospecific Visits}

As expected, the proportion of recipient flowers with dye exponentially decreased with increasing distance to the source plant, on average from $61 \%$ at a distance of $1 \mathrm{~m}$ to $7 \%$ at a distance of $10 \mathrm{~m}$ (fig. 3; table 2). However, the rate of decay varied with donor-recipient combination (table 2). Notably, in experiment D1, decay of the fraction of S. dioica flowers with dye originating from the heterospecific S. latifolia was much faster than that of flowers with dye originating from conspecifics (fig. $3 E$; table 2 , interaction distance $\times$ donor species). The ratio of heterospecific to conspecific spore analogues on $S$. dioica thus declines with increasing distance to source plants. A similar but less pronounced effect was seen in the diurnal experiment DN2, whereas in experiment D2, the strength of the effect varied with replicate (table 2; distance $\times$ donor species $\times$ replicate), and in DN1, it was observed only for female recipients (table 2, distance $\times$ donor species $\times$ sex ).

Because of the lower visitation frequencies of heterospecific compared with conspecific hosts and their steeper decline with distance, the maximum distance at which flowers with dye could be found was much larger for dye originating from conspecifics than from heterospecifics (table 3 ). Using an exponential decay function, the estimated distance at which $1 \%$ of flowers would still carry dye from conspecifics was, averaged over the four experiments, $41.7 \mathrm{~m}$ for $S$. dioica and $28.5 \mathrm{~m}$ for $S$. latifolia; dye from heterospecifics reached only half these distances, 22.0 and $15.3 \mathrm{~m}$, respectively. The differences were more pronounced for males $(58.7$ and $33.4 \mathrm{~m}$ vs. 24.3 and $16.9 \mathrm{~m}$ ) than for females $(38.4$ and $24.7 \mathrm{~m}$ vs. 20.8 and $15.2 \mathrm{~m}$, although the difference between sexes was only significant in DN2; table 3).

\section{Differential Pollinator/Vector Guilds}

Direct observations of visitors showed that S. latifolia was visited during the night mainly by nocturnal moth species, in particular Hadena bicruris and Autographa gamma, which is also active during daytime (table 4). Silene dioica was visited during daytime mainly by several species of bumblebees (mainly Bombus terrestris, Bombus hortorum, and Bombus pascuorum) and hoverflies (mainly Rhingia campestris). Nearly one-third of the insects that were caught carried huge loads of fluorescent dye. Silene latifolia-derived fluorescent dye was detected on five out of 28 nocturnal visitors that were caught, while none of these insects carried $S$. dioica-derived dye. By contrast, $S$. dioica-derived fluorescent dye was detected on eight out of 14 diurnal insect visitors that were caught, of which one insect also carried dye from S. latifolia (table 4).

\section{Phenology and Spatial Structure of Host Species}

In the natural sympatric population, we observed large differences in flowering phenology between the two host species and hence in the time frames during which the fungal demes from $S$. latifolia and the demes from $S$. dioica can be transmitted by insect vectors (fig. 4). Onset of flowering was $4 \mathrm{wk}$ later in S. latifolia than in S. dioica, whereas median diseased flower production was 10 wk later in S. latifolia (end of August, week 35) than in S. dioica (mid-June, week 25) (fig. $4 A$ ). More than two-thirds of all diseased S. dioica flowers in the population had already been produced before the end of June (week 26), while more than $90 \%$ of diseased S. latifolia flowers were not produced until after that week (fig. 4A). Nonetheless, over the entire season, there was only a relatively small phenology-induced shift toward higher average exposure of healthy flowers to spores from conspecifics than 


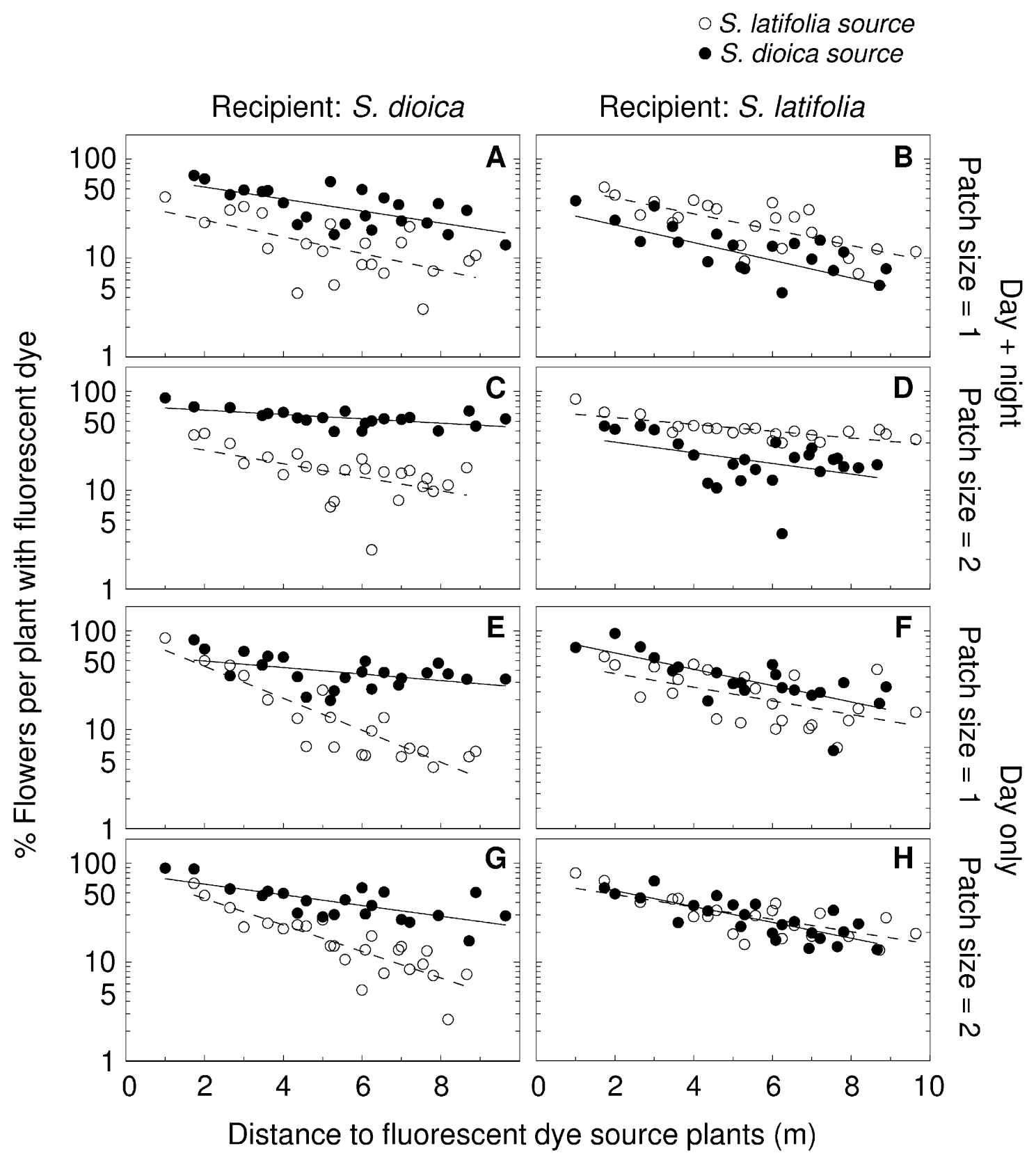

Fig. 3 Proportion of flowers on Silene dioica (left) and Silene latifolia plants (right) with fluorescent dye originating from S. dioica (filled circles) and $S$. latifolia (open circles) as a function of distance from the dye source in four different experiments ( $A, B$, experiment DN1; C, D, experiment DN2; $E, F$, experiment D1; $G, H$, experiment D2). Note the log scale of the $Y$-axis.

to spores from heterospecifics. This was caused in part by the long right tail of the distribution of diseased flower production in $S$. dioica (fig. 4A). As a consequence, both species made a considerable contribution to the total spore pool in the population during a large part of the season (fig. 4B). Another reason for the relatively small shift was the larger overlap in phenology between the two species with respect to healthy flower production (median for S. latifolia, week 32; for $S$. dioica, week 27; fig. 4C) compared with diseased flower production (fig. 4A). The first half of the healthy flowers produced by $S$. dioica (i.e., until week 27; fig. 4C) was ex- posed to spores of which $85 \%$ originated from conspecifics and only $15 \%$ from heterospecifics (fig. 4D), but over the whole season, these percentages were much closer, $57.1 \%$ and $42.9 \%$, respectively. Purely based on phenological differences between the two species, i.e., assuming global and random disease transmission in the population, $S$. dioica would thus have a 1.33-fold higher probability of receiving disease from conspecifics than from heterospecifics. For S. latifolia, the difference was more pronounced; $65.5 \%$ and $35.5 \%$ of healthy flowers were exposed to conspecific and heterospecific spores, respectively, a factor of 1.90 (fig. 4D). 
Table 2

Effects of Replicate Experiment (R) Distance (D) from Dye Source, Donor Species (DS; Dye Source, Silene latifolia or Silene dioica), and Host Sex (SX) of Recipient Species on the Proportion of Flowers on Recipient Plants That Received Dye from the Donor Species

\begin{tabular}{|c|c|c|c|c|c|c|c|c|c|}
\hline & \multirow[b]{2}{*}{ df } & \multicolumn{4}{|c|}{ S. dioica } & \multicolumn{4}{|c|}{ S. latifolia } \\
\hline & & DN1 & DN2 & $\mathrm{D} 1^{\mathrm{a}}$ & D2 & DN1 & $\mathrm{DN} 2$ & $\mathrm{D} 1^{\mathrm{a}}$ & D2 \\
\hline $\mathrm{R}$ & 3 & $9.0^{* * * *}$ & $18.6^{* * *}$ & .0 & $5.7^{* * * *}$ & 1.7 & $6.9^{* * *}$ & .6 & $6.6^{* \ldots * n}$ \\
\hline $\mathrm{D}$ & 1 & $90.3^{* \ldots *}$ & $124.0^{* \ldots * *}$ & $79.4^{* \ldots * *}$ & $209.7^{* * * *}$ & $65.7^{* \ldots *}$ & $78.4^{* * *}$ & $51.5^{* * *}$ & $185.6^{* * *}$ \\
\hline DS & 1 & $138.8^{* \ldots *}$ & $727.9^{* * * *}$ & $65.5^{* \ldots * n}$ & $224.0^{* * * *}$ & $68.6^{* \ldots * n}$ & $96.4^{* * *}$ & $18.4^{\text {n*n }}$ & 1.9 \\
\hline SX & 1 & 3.4 & $32.5^{* \ldots *}$ & .5 & .6 & $4.8^{*}$ & $75.3^{* \ldots * n}$ & $16.5^{* * * *}$ & $9.8^{* * *}$ \\
\hline $\mathrm{D} \times \mathrm{DS}$ & 1 & .1 & $6.4^{*}$ & $31.7^{* * * *}$ & 1.4 & 2.0 & $\ldots$ & .7 & $\ldots$ \\
\hline $\mathrm{D} \times \mathrm{SX}$ & 1 & .1 & $\ldots$ & $4.1^{*}$ & $\ldots$ & .2 & $\ldots$ & $\ldots$ & $8.7^{* * *}$ \\
\hline $\mathrm{DS} \times \mathrm{SX}$ & 1 & .3 & & $\ldots$ & & 2.4 & $5.0^{*}$ & $\ldots$ & $\ldots$ \\
\hline $\mathrm{D} \times \mathrm{R}$ & 3 & $3.9^{* * *}$ & $2.7^{* * *}$ & $\ldots$ & $8.4^{* * * *}$ & $9.2^{* * * *}$ & & .1 & \\
\hline $\mathrm{DS} \times \mathrm{R}$ & 3 & $\ldots$ & $5.5^{* * *}$ & $\ldots$ & $38.8^{* * * *}$ & $8.5^{* \ldots *}$ & $3.2^{*}$ & $10.1^{* * *}$ & $215.2^{* * *}$ \\
\hline $\mathrm{SX} \times \mathrm{R}$ & 3 & $\ldots$ & $6.9^{* * * *}$ & $\ldots$ & & & $13.3^{* * * *}$ & & $\ldots$ \\
\hline $\mathrm{D} \times \mathrm{DS} \times \mathrm{R}$ & 3 & $\ldots$ & $\ldots$ & $\ldots$ & $5.7^{* \ldots * n}$ & $5.5^{* * *}$ & $\ldots$ & $10.2^{* * *}$ & $\ldots$ \\
\hline $\mathrm{D} \times \mathrm{DS} \times \mathrm{SX}$ & 1 & $5.3^{*}$ & $\ldots$ & $\ldots$ & .. & $5.0^{*}$ & $\ldots$ & $\ldots$ & $\ldots$ \\
\hline Error df & & 444 & 479 & 241 & 471 & 424 & 482 & 239 & 491 \\
\hline
\end{tabular}

Note. Data for four different experiments $(\mathrm{DN}=$ day and night visitation; $\mathrm{D}=$ daytime visitation; $1=$ plant species alternating; $2=$ plant species in small patches). Values are quasi- $F$ values from GLM analyses. Ellipses = nonsignificant effects removed from the model.

${ }^{\text {a }}$ For experiment D1, the degrees of freedom for replicate and interactions with replicate are 1 instead of 3.

$* P<0.05$.

${ }^{* *} P<0.01$

*** $P<0.001$

There was also considerable spatial substructure with respect to host species in the sympatric population. For $S$. dioica, median distance to the nearest healthy conspecific and heterspecific neighbor in the population was 0.14 and $6.64 \mathrm{~m}$, respectively. For $S$. latifolia, these distances were 0.28 and 8.60 $\mathrm{m}$ (fig. 5A). Median distances to conspecific and heterospecific inoculum sources were much larger, 2.0 and $22.9 \mathrm{~m}$ for S. dioica and 2.4 and $57.4 \mathrm{~m}$ for S. latifolia (fig. 5B). For $70 \%$ of the S. dioica plants and $89 \%$ of S. latifolia plants, the nearest heterospecific inoculum source was farther away than the nearest conspecific inoculum source (fig. 5C). For $58 \%$ of $S$. dioica and $77 \%$ of $S$. latifolia plants, the nearest heterospecific inoculum source was more than $10 \mathrm{~m}$ farther away than the nearest conspecific inoculum source (fig. 5C).

\section{Discussion}

\section{Role of Vectors in Differentiation within Insect-Vectored Fungal Phytopathogens}

Many phytopathogenic microorganisms, including viruses, bacteria, fungi, and protozoans are transmitted by arthropod vectors. Host-specific visitation behavior of these vectors could potentially mediate host-specific differentiation, host race

Table 3

Estimated Distance from Source Plants at Which the Proportion of Flowers Carrying Dye on Recipient Plants Becomes Smaller Than $1 \%$

\begin{tabular}{|c|c|c|c|c|c|c|c|c|}
\hline & \multicolumn{4}{|c|}{ Silene dioica ${ }^{\mathrm{a}}$} & \multicolumn{4}{|c|}{ Silene latifolia } \\
\hline & \multicolumn{2}{|c|}{ S. dioica ${ }^{\mathrm{b}}$} & \multicolumn{2}{|c|}{ S. latifolia ${ }^{\mathrm{b}}$} & \multicolumn{2}{|c|}{ S. latifolia ${ }^{\mathrm{b}}$} & \multicolumn{2}{|c|}{ S. dioica ${ }^{\mathrm{b}}$} \\
\hline \multicolumn{9}{|c|}{ Male and female recipients combined: } \\
\hline DN1 & 28.7 & $(22.7-38.0)$ & 16.2 & $(13.0-20.6)$ & 23.1 & $(18.6-29.6)$ & 15.4 & $(12.6-19.2)$ \\
\hline DN2 & $\overline{71.1}$ & $(56.0-96.0)$ & 18.7 & $(15.5-23.0)$ & $\overline{40.0}$ & $(34.1-47.8)$ & $\overline{22.2}$ & $(17.7-28.8)$ \\
\hline D1 & $\overline{37.7}$ & $(28.5-53.5)$ & $\overline{12.9}$ & $(11.2-14.8)$ & $\overline{28.1}$ & $(20.9-40.3)$ & $\overline{26.3}$ & $(22.1-31.5)$ \\
\hline D2 & $\overline{29.2}$ & $(24.3-35.9)$ & $\overline{13.6}$ & $(12.1-15.2)$ & 22.9 & $(19.7-27.0)$ & 24.0 & $(20.2-29.2)$ \\
\hline \multicolumn{9}{|l|}{ DN2: } \\
\hline Male & 116.5 & (88.4-168.2) & 17.8 & $(14.7-22.0)$ & 55.0 & $(45.5-68.9)$ & 26.7 & $(20.5-36.6)$ \\
\hline Female & 47.7 & $(37.5-64.3)$ & 20.8 & $(14.7-31.9)$ & 26.9 & $(21.6-34.7)$ & 17.5 & $(13.5-23.4)$ \\
\hline
\end{tabular}

Note. Values $(\mathrm{m})$ and their $95 \%$ confidence intervals (in parentheses) are calculated from parameter estimates of fitted nonlinear regressions $y=a \exp (-b x)$, where $y=\%$ flowers with fluorescent dye on a plant and $x=$ distance from the dye source. $\mathrm{DN}=$ day and night visitation; $\mathrm{D}=$ daytime visitation; 1 = plant species alternating; 2 = plant species in small patches. Underlining indicates that the estimated distances differ significantly $(P<0.05)$ between the two source species for a given recipient species.

${ }^{\text {a Recipient. }}$

b Source. 


\section{Table 4}

Direct Observations of Insect Visitors to Silene latifolia (L) and Silene dioica (D) in the Experimental Plots and the Presence of Fluorescent Dye Originating from the Two Plant Species on Individuals That Were Caught

\begin{tabular}{|c|c|c|c|c|c|}
\hline \multirow{2}{*}{$\begin{array}{l}\text { Visitor group/species } \\
\text { (no. observed) }\end{array}$} & \multicolumn{2}{|c|}{ Visits to } & \multicolumn{3}{|c|}{ Dye from } \\
\hline & $\mathrm{L}$ & $\mathrm{D}$ & $\mathrm{L}$ & $\mathrm{D}$ & None \\
\hline \multicolumn{6}{|l|}{ Night observations: ${ }^{a}$} \\
\hline \multicolumn{6}{|l|}{ Noctuid moths: } \\
\hline Hadena bicruris (18) & 18 & $\ldots$ & 5 & $\ldots$ & 13 \\
\hline Autographa gamma (9) & 7 & 2 & $\ldots$ & $\ldots$ & 9 \\
\hline Plusia sp. (1) & 1 & $\ldots$ & $\ldots$ & $\ldots$ & 1 \\
\hline \multicolumn{6}{|l|}{ Day observations: ${ }^{\mathrm{b}}$} \\
\hline \multicolumn{6}{|l|}{ Bumblebees: } \\
\hline Bombus sp. (17) & 3 & 87 & $\ldots$ & 1 & 1 \\
\hline \multicolumn{6}{|l|}{ Hoverflies: } \\
\hline Rhingia campestris (14) & 6 & 31 & 1 & 7 & 2 \\
\hline Episyrphus sp. (5) & 2 & 3 & $\ldots$ & $\ldots$ & 1 \\
\hline Syrphus sp. (1) & $\ldots$ & 1 & $\ldots$ & $\ldots$ & $\ldots$ \\
\hline \multicolumn{6}{|l|}{ Satyrid butterflies: } \\
\hline Satiridae sp. (1) & ... & 2 & $\ldots$ & $\ldots$ & $\ldots$ \\
\hline \multicolumn{6}{|l|}{ Parasitoid wasps: } \\
\hline Microplitis tristis (1) & $\ldots$ & 1 & ... & $\ldots$ & 1 \\
\hline \multicolumn{6}{|l|}{ Bees: } \\
\hline Apis sp. (1) & $\ldots$ & 1 & $\ldots$ & $\ldots$ & $\ldots$ \\
\hline
\end{tabular}

Note. Ellipses $=$ zero observations.

a 2300-0200 hours (in total, 15-20 h of observations over 10 nights).

b 1200-1700 hours (in total, 215 min of observations over 5 d).

formation, and speciation in the vectored phytopathogens, but as yet, evidence for involvement of vector behavior in such processes is scant. Our study indicates that the role of host fidelity of the pollinator guilds of the closely related host species Silene dioica and Silene latifolia in restricting gene flow between demes of the vectored anther smut fungus Microbotryum violaceum on these two hosts is limited. Although pollinators clearly showed host preference, interspecific transfer of spore analogues in completely mixed experimental plots was still in the order of $30 \%$. It is therefore unlikely that host fidelity of vectors alone plays a major role in the formation or maintenance of sympatric host races of this fungus on the two host species. More likely, it is just one of a combination of factors that is responsible for the observed host-specific fungal differentiation in sympatry. Some evidence for a role of vectors in maintaining differentiation among plant-associated fungi comes from the work of Bultman and Leuchtman (2003). Anthomyiid flies (Botanophila sp.) vector fungal endophytes (Epichloë sp.) of grasses by ingesting fungal gametes and defecating them onto fungal fruiting bodies on ensuing plants, resulting in fertilized fruiting bodies on which their larvae feed. The endophytes Epichloë typhina and Epichloë clarkii are interfertile but appear reproductively isolated. In a sympatric population, where $60 \%$ of gametes was produced by the latter species, flies carried only $4 \%$ E. clarkii gametes, suggesting strong discrimination against the latter species (Bultman and Leuchtman 2003). Although these vectors thus probably contribute to fungal differentiation, in this case, they do not contribute to host-specific fungal differentiation; the two endophytes can occur on the same host grass species, and the specificity of the anthomyiid flies is most likely based on fungal rather than plant cues. The idea that vectors can drive host-specific differentiation among fungal pathogens is therefore still awaiting experimental evidence.

\section{Consequences of Asymmetric Interspecific Visitation}

Even though the observed host fidelity of the pollinator guilds of S. latifolia and S. dioica is unlikely to be strong enough to play a key role in maintaining differentiation among M. violaceum isolates on these two host species in sympatry, the visitation patterns do indicate that pollinators exhibit some degree of host fidelity, even when the two host species are placed in an artificial, fully mixed sympatric setup. Our direct observations confirm results from earlier studies (Baker 1947; Jürgens et al. 1996; Goulson and Jerrim 1997) that $S$. dioica and S. latifolia harbor different main pollinator guilds. Silene dioica is visited during daytime mainly by bumblebee and hoverfly species (Kay et al. 1984; Westerbergh and Saura 1994; Carlsson-Granér et al. 1998), whereas S. latifolia, with its typical moth pollination syndrome, is visited at dusk mainly by nocturnal moths (Brantjes 1976; Shykoff and Bucheli 1995; Altizer et al. 1998). Interspecific visitation has been described for each of the three genera (Goulson and Jerrim 1997). Interestingly, the extent of interspecific visitation appears to be asymmetric. Relatively more dye was transferred from $S$. dioica to $S$. latifolia $(42 \%$ of dye on $S$. latifolia recipients originated from $S$. dioica) than in the reverse direction $(28 \%$ of dye on $S$. dioica originated from S. latifolia). This is consistent with our direct observations of visitors, showing that nocturnal moths are more choosy, visiting more exclusively $S$. latifolia than the day-visiting bumblebees and syrphids that more frequently switch between hosts. As a result of the asymmetric interspecific visitation pattern, fungal strains from S. latifolia are less likely to be transmitted to $S$. dioica than vice versa. Because fungal strains from S. latifolia tend to have higher infection success than strains from $S$. dioica on both host species (van Putten et al. 2003), the directionality of interspecific transfer would increase the prospects for maintaining S. dioica strains in sympatric host populations, as they are less likely to be swamped by $S$. latifolia strains on their native host.

\section{Consequences of Sex-Specific Visitation}

In agreement with earlier studies in S. latifolia (Shykoff and Bucheli 1995; Altizer et al. 1998) and S. dioica (CarlssonGranér et al. 1998), male plants received more visits than female plants, and spore analogues traveled farther on males than on females. The sexual difference appears to be caused mainly by the larger floral display of males; the absolute number of flowers visited per plant was higher for males than for females, whereas no consistent sexual difference was observed for the proportion of open flowers that was visited per plant. Active discrimination against female flowers is suggested to be a common phenomenon in dioecious plants (Bierzychudek 1987 and references therein). The resulting higher number of vector contacts experienced by male plants may contribute to their higher probability to become infected by M. violaceum in the field (Alexander 1989; Thrall and Jarosz 1994; Alexander and Antonovics 1995; Biere and Antonovics 

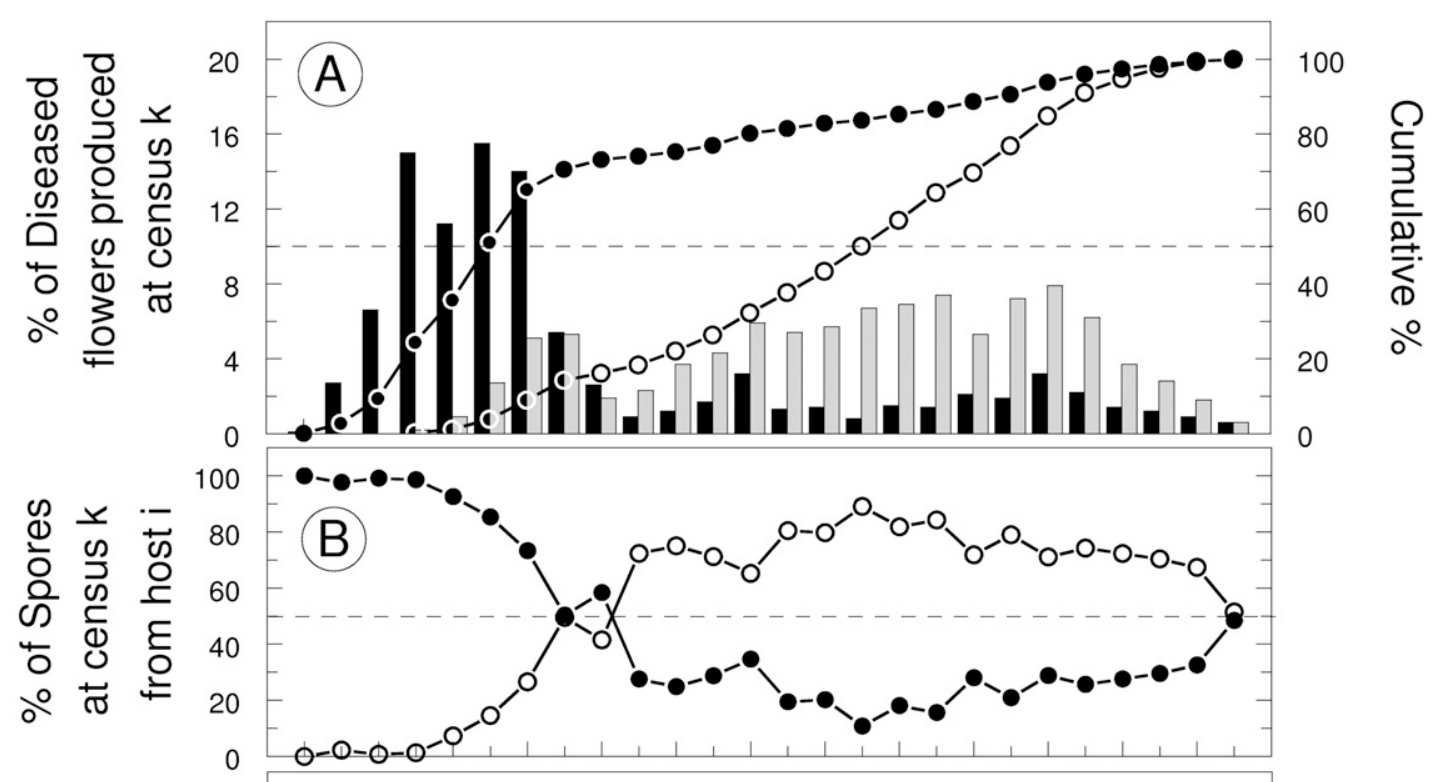

0

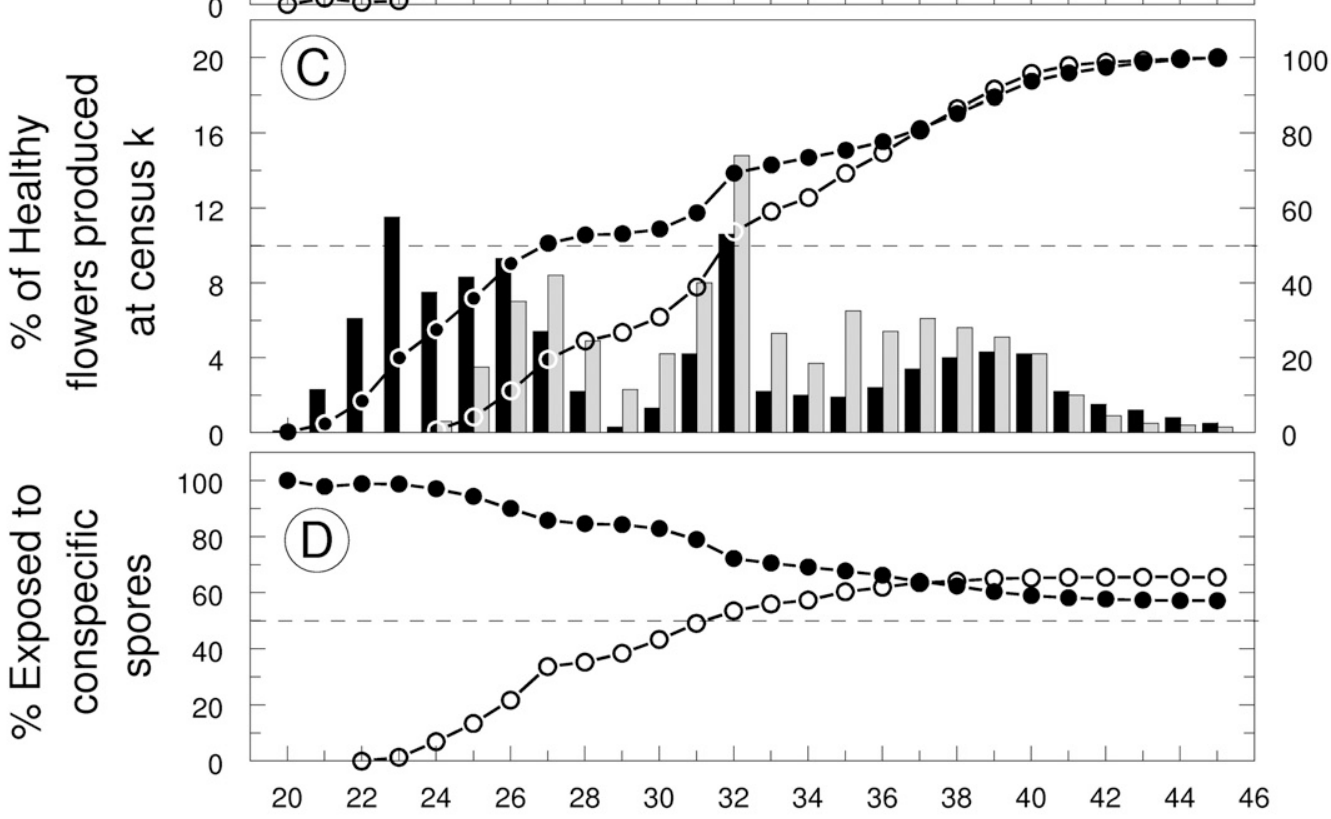

Week number

Fig. 4 Flowering phenology of healthy and diseased plants in a large sympatric population of Silene dioica (black bars, filled circles) and Silene latifolia (gray bars, open circles) based on weekly censuses from late April to late October. A, Percent of the total number of spore-producing flowers per species that was produced at each census interval (bars). Circles represent the cumulative percentage per species. $B$, Contribution (\%) of the two host species to the total number of spore-producing flowers at each census interval. $C$, As in $A$ but for healthy flowers. $D$, Percent of the cumulative number of healthy flowers (see $C$ ) that was exposed to spores originating from conspecifics (see $B$ ).

1996; Biere and Honders 1998), apparently outweighing the lower per-contact infection risk of males that has been observed in some inoculation experiments (Kaltz and Shykoff 2001). Interestingly, the proportion of flowers receiving mixed dye (i.e., dye from both a conspecific and a heterospecific dye source) was also higher in males than in females. Flowers receiving spores from both origins are potential sites for the production of infections that result from an interdeme outcrossing event, generating hybrid fungal offspring and jeopardizing reproductive isolation among fungal demes. Such events are probably rare in nature. Microbotryum violaceum is a highly selfing plant pathogen due to the predominance of so-called intratetrad mating (Hood and Antonovics 2000; Garber and Ruddat 2002). When diploid teliospores germinate, mating occurs predominantly between opposite mating-type products of a single meiosis (basidiospores) that are arranged in a linear tetrad. Even so, outcrossing occurs at low frequency (Baird and Garber 1979), and if vectors bring together teliospores originating from the two host species, interdeme outcrossing can occur. Interestingly, studies by van Putten et al. 

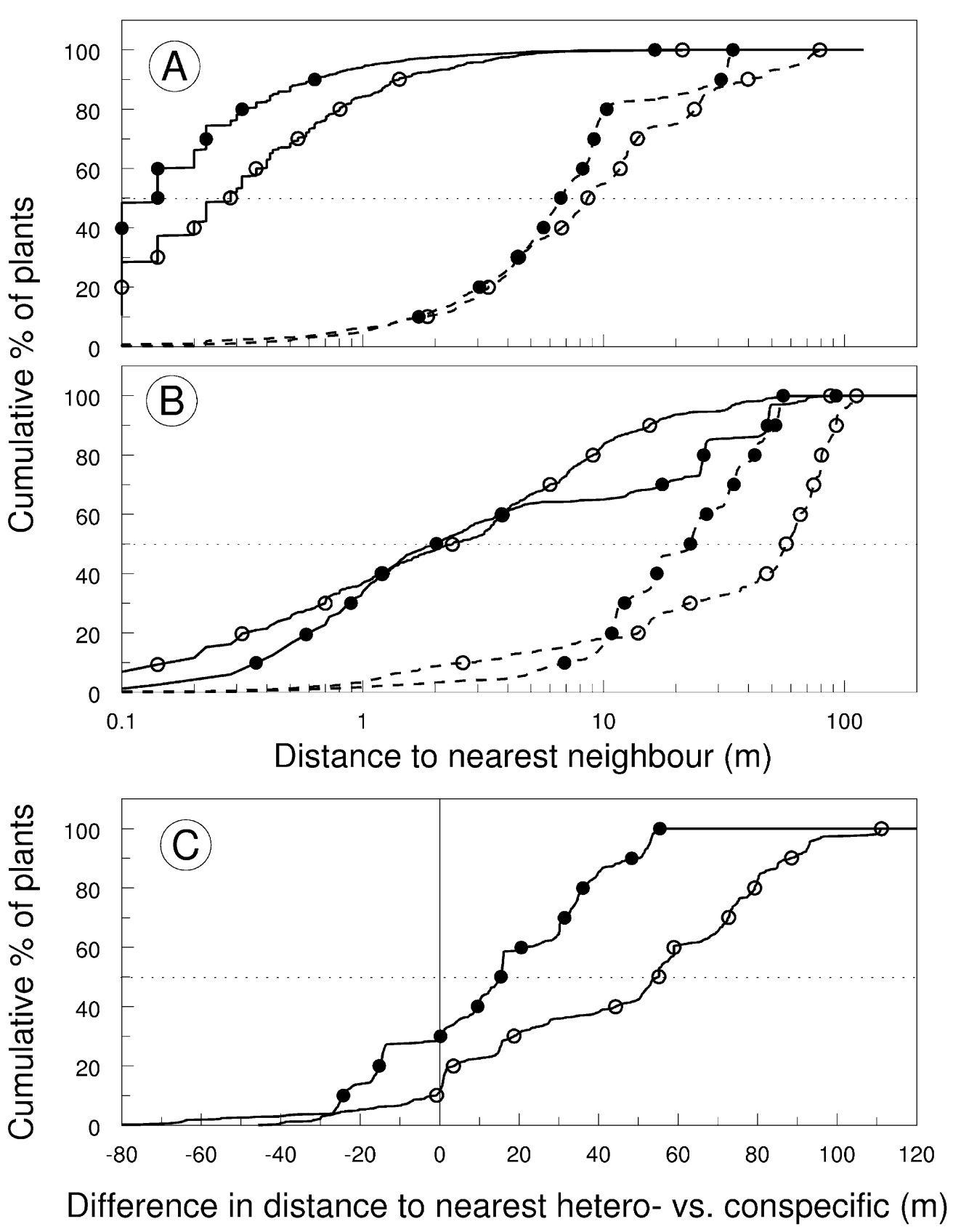

Fig. 5 Characteristics of the spatial structure of Silene dioica (filled circles) and Silene latifolia (open circles) in a large sympatric population. A, Cumulative distribution of the mean distance to a conspecific (solid lines) and heterospecific (dashed line) healthy neighbor. $B$, As in $A$ but for diseased neighbors. $C$, Cumulative distribution of the difference in distance to the nearest heterospecific and conspecific diseased neighbor. Negative values indicate closer proximity of fungal spores from heterospecific than from conspecific neighbors.

(2003) have shown that it is precisely the male plants that are much less suitable hosts for the successful production of mixed infections. Van Putten et al. (2003) inoculated S. latifolia and $S$. dioica plants with mixtures of haploid sporidia (asexual progeny of basidiospores) that originated from teliospores sampled from the two different host species. Whereas in female plants that became infected two-thirds of the produced spores originated from interdeme outcrossing, in male plants, this was roughly only half. Apparently, interdeme outcrossing is advantageous in females but not in males. That mixed-dye loads were most frequently observed on male plants may therefore-in addition to the predominance of intratetrad mating-further limit the potential number of interdeme outcrossings and the extent to which interdeme hybrids are formed in sympatric host populations.

\section{Role of Host Phenology and Spatial Structure in Host-Specific Fungal Differentiation}

The extent of host differentiation between fungal demes on $S$. dioica and $S$. latifolia appears to be larger in allopatry 
than in parapatry or sympatry (van Putten et al. 2005). Yet, significant differentiation has been observed in the largest, most closely sympatric population that we know of and that we used in this study (van Putten 2002; van Putten et al. 2005). Because strains originating from S. latifolia appear to have a higher infection success on both host species (van Putten et al. 2003), maintenance of differentiation and especially maintenance of $S$. dioica-specific strains in sympatry is remarkable. Unfortunately, studies in this population have not extended over sufficiently long periods of time to determine whether the apparent maintenance of host-specific differentiation reflects a transient process or whether it is stable over time. Whether stable or not, if host fidelity is not the driving force reducing current interspecific transfer between fungal demes from the two host species, it is relevant to see whether differences in flowering phenology or spatial substructure of the two host species might be involved in maintaining host-specific differentiation. The species showed large differences in flowering phenology. Median timing of the production of spore-carrying flowers was well over 2 mo later in $S$. latifolia than in $S$. dioica. Surprisingly, our calculations showed that because of the large tails of the distributions and the larger phenological overlap between healthy hosts than between diseased hosts of the two species, the difference in phenology did not result in a vastly higher exposure of healthy flowers to spores originating from conspecifics than from heterospecifics. The ratio of conspecific to heterospecific spores in the population experienced by healthy S. latifolia was around $1.9: 1$; for $S$. dioica, this was only $1.3: 1$. In the studied year and population, assorting based on differences in phenology thus seems to be roughly in the same order of magnitude as assorting based on host fidelity of vectors in the experimental setup, for which we observed ratios of around 1.4 : 1 (58\% conspecific vs. $42 \%$ heterospecific) for S. latifolia and 2.6 : 1 for $S$. dioica (72\% conspecific vs. $28 \%$ heterospecific). Late-flowering plants have very low infection success in natural populations (Biere and Honders 1996b). The latent period of the fungus is in the order of $8-12 \mathrm{wk}$. In late-flowering plants, the fungus has sufficient time neither to grow through the inflorescence and produce new spores within the same season nor to reach the rosette to overwinter successfully and produce a systemic infection. Therefore, the composition of the spore population at the time of early-flowering plants is probably more relevant to assess potential inoculum sources that lead to successful infections than the composition over the entire season. Ratios of conspecific to heterospecific spores for earlier-than-median flowering plants were $6: 1$ for $S$. dioica and $1: 1$ for $S$. latifolia. Such asymmetry may contribute to the maintenance of $S$. dioica strains in sympatry through infection of their early-flowering $S$. dioica hosts.

Even though in the studied sympatric population the two host species co-occur at a spatial scale of sometimes less than $10 \mathrm{~cm}$, we speculate that spatial substructure in the population plays an important role in restricting interspecific transfer of fungal demes from the two host species. The two species grow in patches reflecting different habitat types within the population. Silene dioica grows in the shaded understory of trees and shrubs in the center of the road margin, while S. latifolia grows near the open edges, the sandy road on the one side and the agricultural field margins on the other side. The habitat differentiation probably reflects differential light adaptation (Willmot and Moore 1973). For healthy plants, the nearest heterospecific neighbor in the natural sympatric population was in the order of 6-8 $\mathrm{m}$ farther away than the nearest conspecific neighbor but was still well within a range of $10 \mathrm{~m}$, providing opportunity for interspecific pollen transfer that is evidenced by the presence of ca. $6 \%$ putative hybrids in this population (Biere and Honders 1996b). Opportunities for interspecific spore transfer are probably more limited. The nearest heterospecific inoculum sources for $S$. dioica and $S$. latifolia were on average 18 and $56 \mathrm{~m}$ farther away than the nearest conspecific inoculum source, to which the median distance was in the order of only $2 \mathrm{~m}$ for both species. It is difficult to link these differences in neighbor distances directly to ratios of conspecific versus heterospecific spore transfer from neighbors; this would require experimental studies within natural sympatric host populations. As a rough indication, in the well-mixed experimental plots, with their average density of two plants per square meter, a distance of $2 \mathrm{~m}$ from source plants corresponded to a ca. $50 \%$ probability of a flower to receive fluorescent dye, whereas 20 and $58 \mathrm{~m}$ would represent distances at which this percentage had dropped to values of around $1 \%$ and well below that. This may generate a substantial predominance of conspecific spore deposition. A further restriction of infections by spores originating from heterospecifics may be imposed because disease transmission gradients are generally much steeper than spore dispersal gradients. In $S$. latifolia, experimental spore transmission studies have shown that despite more extensive spore transmission, the occurrence of infections was limited mainly to distances of 6-12 m from a spore source (Alexander 1990; Roche et al. 1995).

\section{Conclusions}

The host fidelity of vectors is unlikely to play a key role in maintaining the observed host-specific differentiation among fungal demes of M. violaceum on the closely related host species $S$. latifolia and $S$. dioica. Rather, we speculate that it is just one of the many factors, including differences in hostflowering phenology and spatial host substructure, that jointly contribute to restriction of gene flow between fungal demes on these two host species in sympatry. Two factors were uncovered that may contribute to the (at least transient) maintenance of $S$. dioica strains that in general appear to be inferior competitors compared with S. latifolia strains on both host species in sympatry. First, interspecific visitation is asymmetric, predominantly from $S$. dioica to S. latifolia, restricting transfer of the competitive superior $S$. latifolia strains onto $S$. dioica. Second, because of the earlier onset of flowering in $S$. dioica, its flowers experience a high probability of exposure to spores from conspecifics compared with heterospecifics during the period that plants are prone to successful systemic infection, much stronger so than S. latifolia. Evidence for vectors as a driving force in host-specific differentiation among fungal plant pathogens is still awaiting.

\section{Acknowledgments}

We wish to thank Manja Kwak for a useful discussion on pollinator behavior, Hans Peter Koelewijn for help 
with data analyses, and Quiny Schümers for help with plant handling in the greenhouse and at our experimental plot. This study was financially supported by the Earth and Life Science Foundation (ALW) of the Netherlands Organization for Scientific Research (NWO), grant 80536-391.

\section{Literature Cited}

Alexander HM 1989 An experimental field study of anther smut disease of Silene alba caused by Ustilago violacea: genotypic variation and disease incidence. Evolution 43:835-847.

1990 Epidemiology of anther smut infection of Silene alba caused by Ustilago violacea: patterns of spore deposition and disease incidence. J Ecol 78:166-179.

Alexander HM, J Antonovics 1995 Spread of anther smut disease (Ustilago violacea) and character correlations in a genetically variable experimental population of Silene alba. J Ecol 83:783794.

Altizer SM, PH Thrall, J Antonovics 1998 Vector behavior and the transmission of anther-smut infection in Silene alba. Am Midl Nat 139:147-163.

Baird ML, ED Garber 1979 Genetics of Ustilago violacea. V. Outcrossing and selfing in teliospore inocula. Bot Gaz 140:89-93.

Baker HG 1947 Infection of species of Melandrium by Ustilago violacea (Pers.) Fuckel and the transmission of the resultant disease. Ann Bot 11:333-348.

1961 The adaptation of flowering plants to nocturnal and crepuscular pollinators. Q Rev Biol 36:64-73.

Berlocher SH, JL Feder 2002 Sympatric speciation in phytophagous insects: moving beyond controversy? Annu Rev Entomol 47:773815.

Biere A, J Antonovics 1996 Sex-specific costs of resistance to the fungal pathogen Ustilago violacea (Microbotryum violaceum) in Silene alba. Evolution 50:1098-1110.

Biere A, S Honders $1996 a$ Host adaptation in the anther smut fungus Ustilago violacea (Microbotryum violaceum): infection success, spore production and alteration of floral traits on two host species and their F1-hybrid. Oecologia 107:307-320.

$1996 b$ Impact of flowering phenology of Silene alba and $S$. dioica on susceptibility to fungal infection and seed predation. Oikos 77:467-480.

1998 Anther smut transmission in Silene latifolia and Silene dioica: impact of host traits, disease frequency, and host density. Int J Plant Sci 159:228-235.

Bierzychudek P 1987 Pollinators increase the cost of sex by avoiding female flowers. Ecology 68:444-447.

Brantjes NBM 1976 Riddles around the pollination of Melandrium album (Mill.) Garcke (Caryophyllaceae) during the oviposition by Hadena bicruris Hufn. (Noctuidae, Lepidoptera). I. Proc K Ned Akad Wet Ser C 79:1-12.

Brasier CM 1987 The dynamics of fungal speciation. Pages 231-260 in ADM Rayner, CM Brasier, D Moore, eds. Evolutionary biology of the fungi. Cambridge University Press, Cambridge.

Bucheli E, B Gautschi, JA Shykoff 2001 Differences in population structure of the anther smut fungus Microbotryum violaceum on two closely related host species, Silene latifolia and S. dioica. Mol Ecol 10:285-294.

Bultman TL, A Leuchtman 2003 A test of host specialization by insect vectors as a mechanism for reproductive isolation among entomophilous fungal species. Oikos 103:681-687.

Bush GL, SR Diehl 1982 Host shifts, genetic models of sympatric speciation and the origin of parasitic insect species. Pages 297-305 in JH Visser, AK Minks, eds. Proceedings of the 5th International Symposium on Insect-Plant Relationships. Pudoc, Wageningen, The Netherlands.

Carlsson-Granér U, T Elmqvist, J Ågren, H Gardfjell, P Ingvarsson
1998 Floral sex ratios, disease and seed set in dioecious Silene dioica. J Ecol 86:79-91.

Dieckmann U, M Doebeli 1999 On the origin of species by sympatric speciation. Nature 400:354-357.

Feder JL 1998 The apple maggot fly, Rhagoletis pomonella: flies in the face of conventional wisdom about speciation? Pages 130-144 in DJ Howard, SH Berlocher, eds. Endless forms. Oxford University Press, New York.

Feder JL, SB Opp, B Wlazlo, K Reynolds, W Go, S Spisak 1994 Host fidelity is an effective premating barrier between sympatric races of the apple maggot fly. Proc Natl Acad Sci USA 91:7990-7994.

Felsenstein J 1981 Skepticism toward Santa Rosalia, or why are there so few kinds of animals? Evolution 35:124-138.

Fry JD 1996 The evolution of host specialization: are trade-offs overrated? Am Nat 148(suppl):S84-S107.

Garber ED, ML Baird, DJ Chapman 1975 Genetics of Ustilago violacea. I. Carotenoid mutants and carotenogenesis. Bot Gaz 136:341-346.

Garber ED, M Ruddat 2002 Transmission genetics of Microbotryum violaceum (Ustilago violacea): a case history. Adv Appl Microbiol 51:107-127.

Goulson D, K Jerrim 1997 Maintenance of the species boundary between Silene dioica and S. latifolia (red and white campion). Oikos 79:115-126.

Gregory PH 1968 Interpreting plant disease gradients. Annu Rev Phytopathol 6:189-212.

Groman JD, O Pellmyr 1999 The pollination biology of Manfreda virginica (Agavaceae): relative contribution of diurnal and nocturnal visitors. Oikos 87:373-381.

Hood ME, J Antonovics 2000 Intratetrad mating, heterozygosity, and the maintenance of deleterious alleles in Microbotryum violaceum (=Ustilago violacea). Heredity 85:231-241.

Ingold CT 1971 Fungal spores: their liberation and dispersal. Clarendon, Oxford.

Ingvarsson PK, L Ericson 1998 Spatial and temporal variation in disease levels of a floral smut (Anthracoidea heterospora) on Carex nigra. J Ecol 86:53-61.

Jeger MJ 1990 Mathematical analysis and modeling of spatial aspects of plant disease epidemics. Pages 53-95 in J Kranz, ed. Epidemics of plant disease: mathematical analysis and modeling. 2nd ed. Springer, New York.

Jennersten O 1983 Butterfly visitors as vectors of Ustilago violacea spores between caryophyllaceous plants. Oikos 40:125-130.

Jürgens A, T Witt, G Gottsberger 1996 Reproduction and pollination in central European populations of Silene and Saponaria species. Bot Acta 109:316-324.

- 2002 Flower scent composition in night-flowering Silene species (Caryophyllaceae). Biochem Syst Ecol 30:383-397.

Kaltz O, JA Shykoff 2001 Male and female Silene latifolia plants differ in per-contact risk of infection by a sexually transmitted disease. J Ecol 89:99-109.

Kay QON, AJ Lack, FC Bamber, CR Davies 1984 Differences between sexes in floral morphology, nectar production and insect visits in a dioecious species, Silene dioica. New Phytol 98:515-529.

Kondrashov AS, FA Kondrashov 1999 Interactions among quantitative traits in the course of sympatric speciation. Nature 400:351-354.

Perlin MH 1996 Pathovars or formae speciales of Microbotryum violaceum differ in electrophoretic karyotype. Int J Plant Sci 157: $447-452$. 
Perlin MH, C Hughes, J Welch, S Akkaraju, D Steinecker, A Kumar, B Smith, et al 1997 Molecular approaches to differentiate subpopulations or formae speciales of the fungal phytopathogen Microbotryum violaceum. Int J Plant Sci 158:568-574.

Prentice HC, O Mastenbroek, W Berendsen, P Hogeweg 1984 Geographic variation in the pollen of Silene latifolia ( $S$. alba, S. pratensis): a quantitative morphological analysis of population data. Can J Bot 62:1259-1267.

Rice WR, GW Salt 1990 The evolution of reproductive isolation as a correlated character under sympatric conditions: experimental evidence. Evolution 44:1140-1152.

Roche BM, HM Alexander, AD Maltby 1995 Dispersal and disease gradients of anther-smut infection of Silene alba at different life stages. Ecology 76:1863-1871.

Roy BA 1994 The use and abuse of pollinators by fungi. Trends Ecol Evol 9:335-339.

Shykoff JA, E Bucheli 1995 Pollinator visitation patterns, floral rewards and the probability of transmission of Microbotryum violaceum, a venereal disease of plants. J Ecol 83:189-198.

Sowig P 1989 Effects of flowering plants patch size on species composition of pollinator communities, foraging strategies, and resource partitioning in bumblebees (Hymenoptera, Apidae). Oecologia 78:550-558.

Taylor JW, DJ Jacobson, MC Fisher 1999 The evolution of asexual fungi: reproduction, speciation and classification. Annu Rev Phytopathol 37:197-246.

Thomson JD, MV Price, NM Waser, D Stratton 1986 Comparative studies of pollen and fluorescent dye transport by bumblebees visiting Erythronium grandiflorum. Oecologia 69:561-566.

Thrall PH, A Biere, J Antonovics 1993 Plant life-history and disease susceptibility: the occurrence of Ustilago violacea on different species within the Caryophyllaceae. J Ecol 81:489-498.
Thrall PH, AM Jarosz 1994 Host-pathogen dynamics in experimental populations of Silene alba and Ustilago violacea. 1. Ecological and genetic determinants of disease spread. J Ecol 82: 549-559.

Vánky K 1998 The genus Microbotryum (smut fungi). Mycotaxon 67:33-60.

van Putten WF 2002 On host race differentiation in smut fungi. PhD diss. University of Utrecht.

van Putten WF, A Biere, JMM Van Damme 2003 Intraspecific competition and mating between fungal strains of the anther smut Microbotryum violaceum from the host plants Silene latifolia and $S$. dioica. Evolution 57:766-776.

2005 Host-related genetic differentiation in the anther smut fungus Microbotryum violaceum in sympatric, parapatric and allopatric populations of two host species Silene latifolia and $S$. dioica. J Evol Biol 18:203-212.

Via S, AC Bouck, S Skillman 2000 Reproductive isolation between divergent races of pea aphids on two hosts. II. Selection against migrants and hybrids in the parental environments. Evolution 54: 1626-1637.

Westerbergh A, A Saura 1994 Gene flow and pollinator behavior in Silene dioica populations. Oikos 71:215-224.

Willmot A, PD Moore 1973 Adaptation to light intensity in Silene alba and S. dioica. Oikos 24:458-464.

Wood TK, KJ Tilmon, AB Shantz, CK Harris, J Pesek 1999 The role of host-plant fidelity in initiating insect race formation. Evol Ecol Res 1:317-332.

Young HJ 2002 Diurnal and nocturnal pollination of Silene alba (Caryophyllaceae). Am J Bot 89:433-440.

Zillig H 1921 Über spezialisierte Formen beim Antherenbrand, Ustilago violacea (Pers.) Fuck. Zentralbl Bakteriol Parasitenk 53:33-74.

Zogg H 1985 Brandpilze Mitteleuropas. Crypt Helvet 16:1-277. 